\section{Predator-prey interaction in arthropods}

\section{A. F. G. Dixon}

The Dynamics of Arthropod PredatorPrey Systems. By M. P. Hassell. Pp. 237. (Princeton University Press: Princeton, New Jersey, and Guildford, UK, 1978.) Hardback \$20; £10.70; paperback $\$ 8.75 ; £ 4.40$.

Dr HASSEll has given us a lucid, clearly illustrated and eminently readable account of the development of analytical models of parasite-host interactions. This book is a most welcome exposition and summary of the current position in a rapidly developing aspect of ecology to which the author himself has been a major contributor.

Starting with the Nicholson and Bailey model the author develops step by step elegant analytical models framed in difference equations. This is achieved by the incorporation of more biologically significant parameters into the model. First, it is shown that stability can be predicted if an expression for density dependence is incorporated. A consideration of the functional responses of predators to prey density reveals the difficulties of extending relationships derived from studying mainly parasitoids. In true predators the search rate and handling time vary with stage of development of the predator and size of the prey, and this complexity poses difficulties in modelling this set of interactions. Consideration is given to the consequences of non-random search by a predator as opposed to the random search assumed by Nicholson and Bailey. More realistic prey and predator distributions tend to make the interaction very complex and difficult to explore analytically. However, the author shows that descriptive models have been useful in this context.

Next is revealed the powerful stabilising effect of mutual interference among searching parasites on parasitehost interactions, the constant area of discovery assumed by Nicholson and Bailey being a special case. However, although a widespread phenomenon in laboratory studies of parasite searching, it should be stressed that the extent to which mutual interference occurs in the field and the significance thereof still needs to be resolved. Many of the laboratory studies on mutual interference have been done at unrealistic densities. In considering the predator rate of increase the author reveals another difference between predators and parasitoids. Prey density influences development, survival and fecundity in predators. If these factors are to be incorporated then the author suggests that we may have to abandon simple time dependent difference equations in favour of mathematically less tractable models.

Switching by predators from eating one prey species, to eating predominantly another species, as the proportion of the alternative prey increases, is shown to stabilise prey populations providing the predator population remains constant. Likewise, if switching is shown by the top predator in a community it can enable competing prey species to coexist. This is followed by a consideration of how it is possible for competing predators and hyperparasitoids to coexist.

The book ends with a most useful chapter on the theoretical basis for biological control which builds on the previous chapters. This reveals that an ideal parasitoid for use in biological control programme, all other things being equal, is one that has a high search rate and a marked ability to aggregate in areas of high host density; and it is argued that these are more likely to be attributes of specific rather than generalist parasitoids. However,

\section{Creative personality}

\section{Macdonald Critchley}

Chase, Chance and Creativity: The Lucky Art of Novelty. By J. H. Austin. Pp. 237. (Columbia University Press: New York, and Guildford, UK, 1978.) $\$ 16.20$.

Nor for a long time have I enjoyed a technical apologia so much. Disjointed it may be, but the book is none the worse for that. Obviously the author is not only a biochemist of conspicuous ability, but he is something much greater, a thinker who writes well, and who is versed in the humanities. The book opens in a naive, autobiographical but intensely interesting fashion. We learn how as a junior hospital officer his interest was captured by a fascinating and argumentative case-conference between two of America's outstanding neurologists. His stint in the pathological laboratory was highlighted by the opportunity to study that rare and deadly disorder, metachromatic leuco- the case of the biological control of winter moth in Canada is used to show that when 'things are not equal' then predicting the outcome is difficult. Multiple introductions of parasitoids are shown now to be justified, as additional species will either coexist with the first species or replace it, and, whatever, the outcome, the equilibrium density of the host will fall.

The author justifies the book's title by regarding parasitoids as simple predators. He stresses that "true predatorprey models need to recover from the neglect at the hands of essentially parasitoid models". Only further study will reveal just how much of a special case the parasitoid-host interaction is and whether it can be usefully applied to the arthropod predator-prey system.

This book will undoubtedly be the standard text for both students and research workers in this field for some time to come. It is also a tribute to Nicholson and Bailey who, although unable to model the stability they observed in insect populations in the field, nevertheless produced a model which has been developed by the author and others to further our understanding greatly. At $£ 4.40$ the paperback version. is excellent value.

A. F. G. Dixon is Professor of Biology at the University of East Anglia, Norwich, UK.

dystrophy. $\mathrm{He}$ became intrigued by the presence of highly coloured urinary deposits which in an odd fashion changed in hue from reddish-purple to a vivid golden brown. What was their nature and what was the meaning of their metamorphosis? Patiently over the ensuing years Dr Austin pursued his quest, following one clue after another, communicating with other workers far and wide. Eventually he narrowed down the responsible factor to a deficiency in the enzyme sulphatase A. This accomplishment led the author to investigate the nature of the Lafora deposits within the neurons in cases of myoclonus epilepsy. They proved to be comprised essentially of a glucose polymer. Important findings such as these inspired Dr Austin to extend his investigations into the chemistry of Alzheimer's disease and then the ageing of the brain.

This introduction leads on to sections 2 and 3 , in which we are introduced to such fascinating topics as the nature of scientific discovery; the role played by mere lucky chance; the factor of intellectual preparedness; and the place occupied in research by serendipity. Concerning the latter, Dr Austin submits an allied but deviant conception which he calls "altamirage". This term was named after the "discovery" 